\title{
Preliminary assessment of correlation between T-lymphocyte responses and control of porcine reproductive and respiratory syndrome virus (PRRSV) in piglets born after in-utero infection of a type 2 PRRSV
}

\author{
Sang-Ho Cha ${ }^{1}$, Carey Bandaranayaka-Mudiyanselage ${ }^{2}$, Chandima B. Bandaranayaka-Mudiyanselage ${ }^{2}$, \\ Dharani Ajiththos ${ }^{3}$, Kyoung-Jin Yoon ${ }^{4}$, Kathleen A. Gibson ${ }^{4}$, Ji-Eun Yu ${ }^{1}$, In-Soo Cho ${ }^{1}$, \\ Stephen S. Lee ${ }^{5}$, Chungwon J. Chung ${ }^{2,3, *, \dagger}$ \\ ${ }^{1}$ Animal and Plant Quarantine Agency, Gimcheon 39660, Korea \\ ${ }^{2}$ VMRD Inc., Pullman, WA 99163, USA \\ ${ }^{3}$ Department of Veterinary Microbiology and Pathology, Washington State University, Pullman, WA 99163, USA \\ ${ }^{4}$ Department of Veterinary Diagnostic and Production Animal Medicine, College of Veterinary Medicine, Iowa State University, \\ Ames, IA 50011, USA \\ ${ }^{5}$ University of Idaho, Moscow, ID 83843, USA
}

(Received: November 11, 2017; Revised: February 10, 2018; Accepted: February 14, 2018)

\begin{abstract}
A preliminary study into the protective mechanisms of adaptive immunity against porcine reproductive and respiratory syndrome virus (PRRSV) in piglets $(n=9)$ born to a gilt challenged intranasally with a type-2 PRRSV. Immune parameters (neutralizing antibodies, $\mathrm{CD}^{+} \mathrm{CD}^{+}, \mathrm{CD}^{+} \mathrm{CD}^{+}, \mathrm{CD}^{+} \mathrm{CD} 4^{+} \mathrm{CD}^{+}$T-lymphocytes, and PRRSVspecific interferon (IFN)- $\gamma$ secreting T-lymphocytes) were compared with infection parameters (macro- and microscopic lung lesion, and PRRSV-infected porcine alveolar macrophages (CD172 $\alpha^{+}$PRRSV-N ${ }^{+}$PAM) as well as with plasma and lymphoid tissue viral loads. Percentages of three T-lymphocyte phenotypes in 14-days post-birth (dpb) peripheral blood mononuclear cell (PBMC) had significant negative correlations with percentages of CD172 $\alpha^{+}$PRRSV-N ${ }^{+}$PAM $(p<0.05)$ as well as with macroscopic lung lesion $(p<0.01)$. Plasma and tissue viral loads had significant $(p<0.05)$ negative correlations with $\mathrm{CD}^{+} \mathrm{CD}^{+} \mathrm{CD}^{+}$T-lymphocyte percentage in $\mathrm{PBMC}$. Frequencies of $\mathrm{CD}^{+} \mathrm{CD} 8^{+}$and $\mathrm{CD}^{+} \mathrm{CD}^{+}$T-lymphocytes in 14-dpb PBMC had significant negative correlations with of lymph node $(p=0.04)$ and lung $(p=0.002)$ viral loads. IFN- $\gamma$-secreting T-lymphocytes frequency had a significant negative correlation with gross lung lesion severity $(p=0.002)$. However, neutralizing antibody titers had no significant negative correlation $(p>0.1)$ with infection parameters. The results indicate that T-lymphocytes contribute to controlling PRRSV replication in young piglets born after in-utero infection.
\end{abstract}

Keywords: T-lymphocyte, neutralizing antibodies, porcine reproductive and respiratory syndrome virus

\section{Introduction}

Porcine reproductive and respiratory syndrome (PRRS) was first recognized in the United States and Europe as 'Mystery Swine Disease' in mid-1980s. The disease characterized by manifestation of reproductive failure and respiratory distress in swine herds had been subsequently reported from Asia and other pig-producing areas between the late 1980s and early 1990s [7, 31]. The causative agent of this globally epidemic, economically important porcine disease was then identified as a member of the Arteriviridae family, which contains a single-stranded positive-sense RNA genome of approximately $15 \mathrm{~Kb}$ in the order of Nidovirales. Porcine reproductive and respiratory syndrome virus (PRRSV) is divided into two major genotypes: type-1 PRRSV (European type) and type-2 PRRSV (North American type).

Vaccination with attenuated live viruses has been used to control clinical PRRS in many countries $[2,26]$. However, this conventional vaccine formulation using a few selected PRRSV isolates has not been satisfactory to protect swine herds affected with various PRRSV isolates, possibly due to induction of ineffective immune response, high antigenic variation among isolates and a possible reversion to virulence of attenuated vaccine strains $[1,24]$. Up to date, neu-

\footnotetext{
*Corresponding author

Tel: +1-631-323-3429, Fax: +1-631-323-3097

E-mail: chungcw@vetmed.wsu.edu

'Present address: Plum Island Animal Disease Center, Greenport, NY 11944, USA
} 
tralizing antibodies have been considered as an indicator of protective immunity in vaccinated pigs. However, neutralizing antibodies are often induced in a delayed mode in vaccinated pigs [21, 34] and not efficacious enough to prevent pigs from being affected by PRRS [3, 13]. Furthermore, neutralizing antibodies are protective only against antigenically homologous viruses, while partial or no protective against heterologous strains of PRRSV [17].

Cell-mediated immunity (CMI) against PRRSV appears in two to four weeks after infection reaching to a peak response in four to seven weeks when measured by interferon (IFN)- $\gamma$ secretion and lymphocyte proliferation [22, 33]. The information on the efficacy and mechanism of PRRSV-specific Tlymphocytes is lacking with conflicting reports, particularly on protective effect of cytotoxic T-lymphocytes (CTL) in PRRSV-infected pigs [20,33].

In-utero infection of PRRSVs resulted in still-birth and death of fetuses, and varying degree of clinical syndromes accompanying with viremia and development of PRRSV-specific-antibodies in live piglets $[12,29]$. The present study was conducted to characterize adaptive immune responses associated with control of lung lesion, virus replication in tissues and viremia pattern in piglets born to a gilt exposed to a type-2 PRRSV strain at the late gestation.

\section{Materials and Methods}

\section{Preparation of PRRSV}

A Type 2 PRRSV $_{\mathrm{SD}_{23983}}$ [11] was used in this study. Propagation and titration of this virus were carried out as previously described $[5,15,27]$.

\section{Animals and viral challenge}

A 12-month-old sexually mature gilt negative for PRRSV, porcine circovirus and porcine epidemic diarrhea virus was purchased and transferred into an isolation facility at Washington State University, and bred by artificial insemination using the commercial semen from a PRRSV- and PCV-free boar. The pig was maintained in the facility for the entire study period. At 98 days of gestation, the pregnant gilt was intranasally inoculated with $1.58 \times 10^{4} \mathrm{TCID}_{50}$ of PRRSV $\mathrm{SD} 23983_{\text {. }}$ Nine piglets live born to the gilt were bled at 0 (before feeding colostrum), 7- and 14-days post-birth ( $\mathrm{dpb}$ ) for serum and peripheral blood mononuclear cells (PBMCs). At 14-dpb (33-day post-inoculation), the piglets were euthanized and pulmonary alveolar macrophage (PAM) was obtained from lungs of the all nine piglets. Macroscopic and microscopic lung lesions were examined per previously described methods [12]. At necropsy, several regional lymph nodes (medial retropharyngeal, tracheobronchial, mesenteric, inguinal, submandibular, and mediastina lymph nodes), tonsil, lung and spleen were collected, and homogenate was made from each tissue for viral load quantitation. Animal handling and care was performed as per the animal use protocol (IACUC No. 04372) approved by Institutional Animal Care and Use Com- mittee at Washington State University.

\section{Real-time reverse transcriptase-polymerase chain reaction (RT-PCR)}

Real-time RT-PCR on various samples was performed at Iowa State University Veterinary Diagnostic Laboratory as per the established protocol using VetMax NA and EU PRRSV reagents (Applied Biosystems, USA). PCR reactions were done per the manufacturer's instructions using a 7500 Fast Real-Time PCR System (Applied Biosystems). The thresholds for NA and EU PRRSVs were set at 0.10 and 0.05 , respectively. A cycle threshold $\left(C_{T}\right)$ of $<37$ cycles was used as cut-off for positive on the assay. A negative control without RNA and a positive control provided in the kit were added to each PCR plate along with positive and negative extraction controls.

\section{Preparation of PBMCs and storage}

Swine PBMCs were isolated from fresh venous blood mixed with $5 \mathrm{mM}$ EDTA (final concentration) by centrifugation on a discontinuous gradient using Lymphoprep (1.077 g/ $\mathrm{mL}$, STEMCELL Technologies, Canada) as previously described $[19,5]$.

Analysis of T-lymphocyte subpopulations and PRRSVinfected alveolar macrophages by flow cytometry

To analyze T-lymphocyte subpopulations in PBMC collected at 14-dpb, staining of T-lymphocytes was performed using phenotype-specific monoclonal antibodies and secondary antibody conjugates per the method previously described [11]. Monoclonal antibodies (MAbs) used in surface staining were anti-CD3 (8E6 clone, IgG1 isotype; VMRD, USA), anti-CD8 (PT81B clone, IgG2b clone; VMRD) and antiCD4-PerCP-Cy5.5 (BD Pharmingen, USA). The secondary antibody conjugates for anti-CD3 and anti-CD8 MAbs were goat anti-mouse IgG1 labeled with fluorescein isothiocyanate (FITC) (Life Technologies, USA) and goat anti-mouse IgG2b conjugated with R-phycoerythrin (R-PE) (Life Technologies), respectively. To determine the proportion of PAM cells harboring PRRSV collected from lung of piglets, surface staining of CD172 $\alpha$ molecule as a PAM cell marker and intracellular staining of PRRSV nucleocapsid $(\mathrm{N})$ protein were performed using CD172 $\alpha$ - and PRRSV-N-specific monoclonal antibodies (clones 74-22-15 and 2D6, respectively) and secondary anti-mouse antibodies labelled with FITC or R-PE per the method previously described [6]. The stained cells were analyzed with a FACSCalibur analytical flow cytometer (BD, USA).

\section{IFN- $\gamma$ enzyme-linked immunospot (ELISpot) assay}

ELISpot assay was carried out to assess PRRSV-specific Tlymphocyte responses using a commercial assay (Mabtech, Sweden) as per manufacturer's instruction. The detailed methods for porcine PBMC stimulation and calculating significant spot-forming unit (SFU) were described previously [5]. 


\section{Fluorescent focusing neutralization assay}

The PRRSV neutralizing antibody response in serum was measured using fluorescent focus neutralizing assay as previously described [5, 32].

\section{Statistical analysis}

Statistical correlation between immune parameters and infection parameters measured on the 9 piglets was analyzed by Spearman's rank correlation coefficient. Hypothesis tests based on these correlation coefficients were carried out by determining if different parameters had a significant $(p<$ $0.05)$ nonzero correlation each other. All statistical analyses were performed using $\mathrm{R}$ software from the $\mathrm{R}$ foundation for Statistical Computing (Austria).

\section{Results}

Piglets developed PRRSV-specific immune responses after in-utero infection of $\mathrm{PRRSV}_{\mathrm{SD23983}}$

Nine piglets born to a gilt intranasally inoculated with type-2 PRRSV $\mathrm{SD} 23983$ at the late gestation were viremic at the day of birth before suckling colostrum, clearly demonstrating in-utero infection. The proportion of CD172 $\alpha^{+}$PRRSV$\mathrm{N}^{+}$PAM harboring PRRSV ranged from $8.0 \%$ to $42.2 \%$ among the piglets as determined by surface and intracellular staining and flow cytometry analysis. The macroscopic lung lesion score varied among the piglets, ranging between 5\% and $50 \%$ of total lung surface. Similarly, the degree of microscopic lesion in lung tissue was varying from mild to severe lesion caused by the replication of PRRSV (Fig. 1). Besides lung tissues, PRRSV RNA was also detected in spleen and mixed lymph nodes of all nine piglets (Table 1).

Six of nine piglets had significantly ( $\geq 5 \mathrm{SE}$ of negative control SFU) high PRRSV-specific T-lymphocyte responses after in-utero infection as determined by ELISpot assay (Table 2). PRRSV-specific IFN- $\gamma$ secreting T-lymphocyte response was particularly highly significant $(>100 \mathrm{SFU}$ and $>5 \mathrm{SE})$ in piglets 1 and 7, moderately significant (50-100 SFU and 5 SE) in piglets 2 and 9, and weakly significant $(<50$ $\mathrm{SFU})$ in piglets 3 and 6 . Frequencies of three different phe-
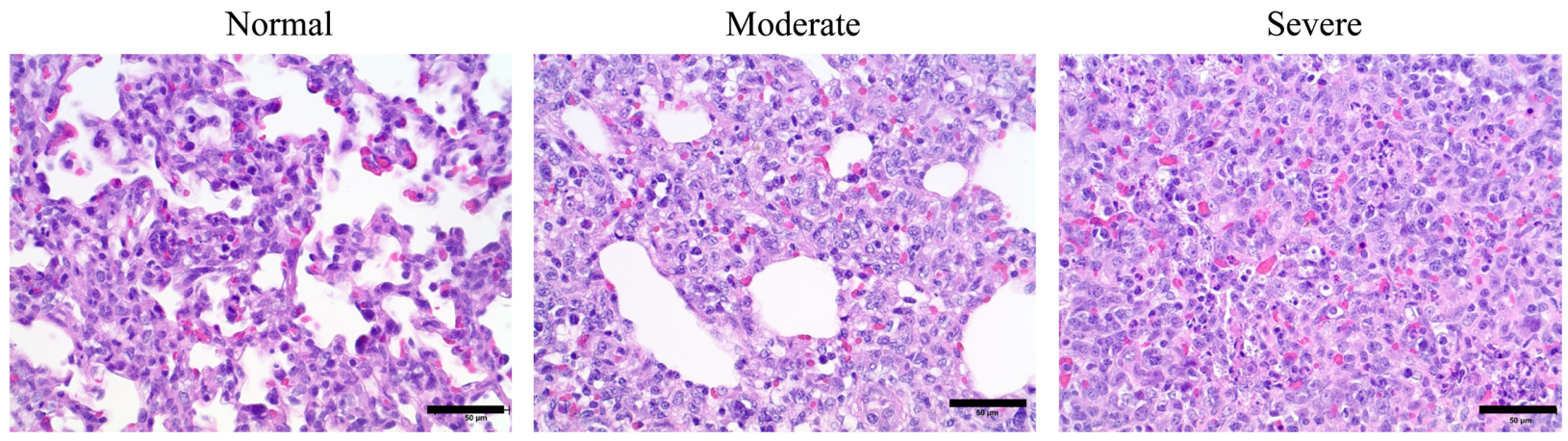

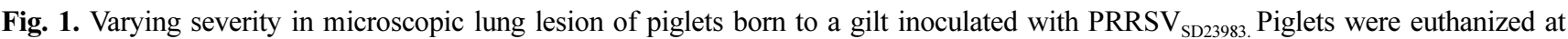
14-dpb and subjected to necropsy and histological analysis. Representative pictures from piglets with mild to normal (piglet 1), moderate (piglet 2) and severe (piglet 8) lung lesions were presented as a supplementary data to the summary in Table 1 . Scale bars $=50 \mu \mathrm{m}$.

Table 1. Analysis on infection parameters in piglets born after in-utero porcine reproductive and respiratory syndrome virus (PRRSV) infection

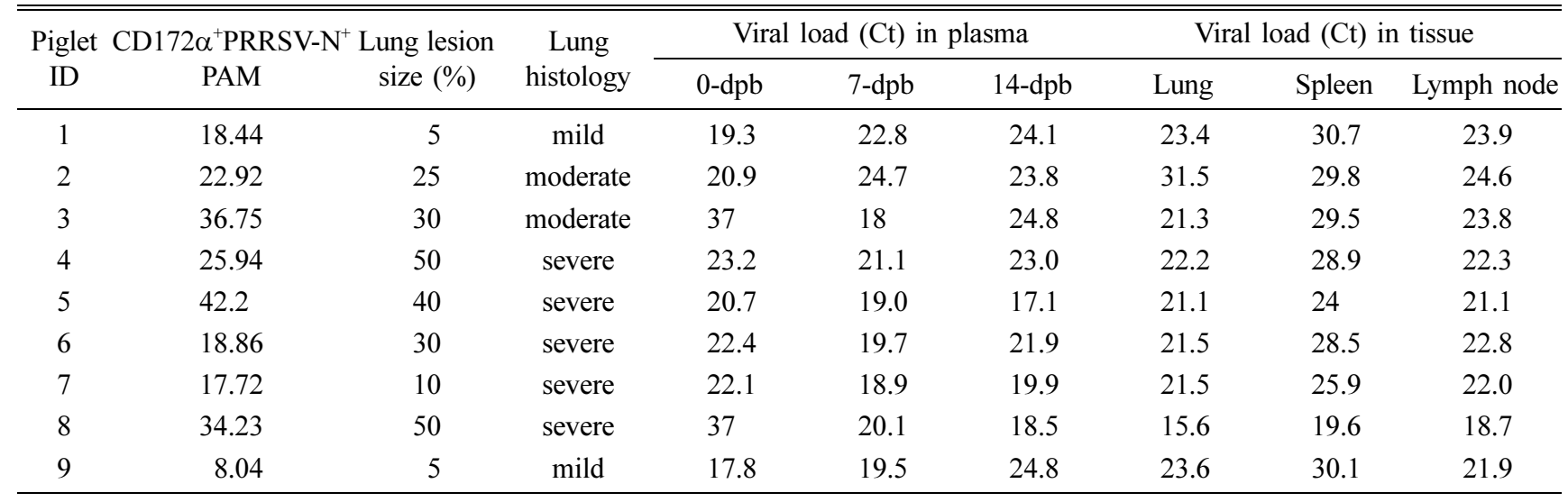

Ct value was obtained by real time RT-PCR. CD172 $\alpha^{+}$PRRSV-N $^{+}$PAM, macroscopic lung lesion, lung histology and tissue viral loads were analyzed using PAMs and tissues collected at 14 days post-birth (dpb). RT-PCR, reverse transcriptase polymerase chain reaction; PAM, pulmonary alveolar macrophage. 
12 Sang-Ho Cha, Carey Bandaranayaka-Mudiyanselage, Chandima B. Bandaranayaka-Mudiyanselage, Dharani Ajjththos, Kyoung-Jin Yoon, Kathleen A. Gibson, Ji-Eun Yu, In-Soo Cho, Stephen S. Lee, Chungwon J. Chun

Table 2. Analysis on immune parameters in piglets born after in-utero PRRSV infection

\begin{tabular}{|c|c|c|c|c|c|c|c|}
\hline \multirow{2}{*}{ Piglet ID } & \multicolumn{3}{|c|}{ VN titer $\left(\log _{2}\right)$} & \multicolumn{3}{|c|}{ T-lymphocyte subpopulation frequency } & \multirow{2}{*}{$\begin{array}{c}\text { SFU*/million } \\
\text { PBMC }\end{array}$} \\
\hline & $0-\mathrm{dpb}$ & 7-dpb & 14-dpb & $\mathrm{CD}^{+} \mathrm{CD}^{+}$ & $\mathrm{CD}^{+} \mathrm{CD}^{+} \mathrm{CD}^{+}$ & $\mathrm{CD}^{+} \mathrm{CD}^{+}$ & \\
\hline 1 & 2 & 3 & 4 & 24.37 & 2.48 & 7.15 & $329+$ \\
\hline 2 & 1 & 3 & 4 & 15.42 & 2.77 & 11.5 & $51+$ \\
\hline 3 & 1 & 4 & 5 & 11.50 & 0.87 & 4.96 & $30+$ \\
\hline 4 & 2 & 3 & 4 & 10.27 & 2.15 & 10.67 & 9 \\
\hline 5 & 2 & 3 & 5 & 4.45 & 0.51 & 5.89 & 60 \\
\hline 6 & 2 & 2 & 3 & 12.43 & 1.90 & 8.08 & $17+$ \\
\hline 7 & 3 & 4 & 4 & 25.01 & 1.17 & 6.39 & $132+$ \\
\hline 8 & 3 & 1 & 4 & 1.61 & 0.40 & 5.25 & 5 \\
\hline 9 & 4 & 2 & 4 & 11.47 & 2.47 & 9.06 & $73+$ \\
\hline
\end{tabular}

*Spot-forming unit (SFU) numbers are mean SFU/10 $0^{6}$ peripheral blood mononuclear cell (PBMC) minus the mean of the appropriate unstimulated control; those adjusted SFU that were greater than the unstimulated control SFU mean plus 5 times the SE were scored as positive and marked with $\mathrm{a}+$ in the table. T-lymphocyte subpopulation frequency and SFU of PRRSV specific interferon (IFN)- $\gamma$ secreting cells were analyzed using PBMC collected at 14 days post-birth.

A

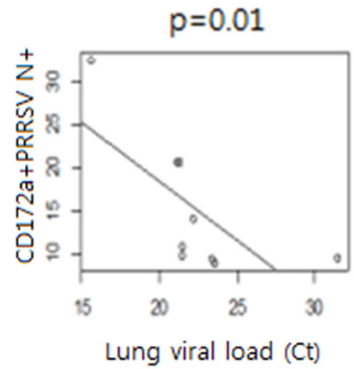

B

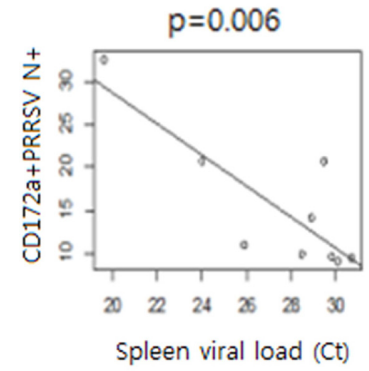

C

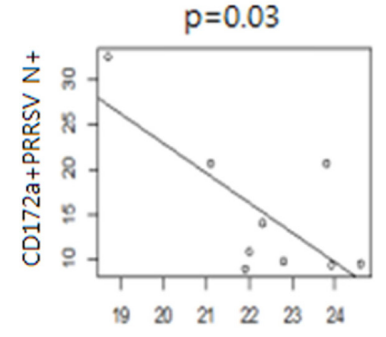

Lymph nodes viral load (Ct)
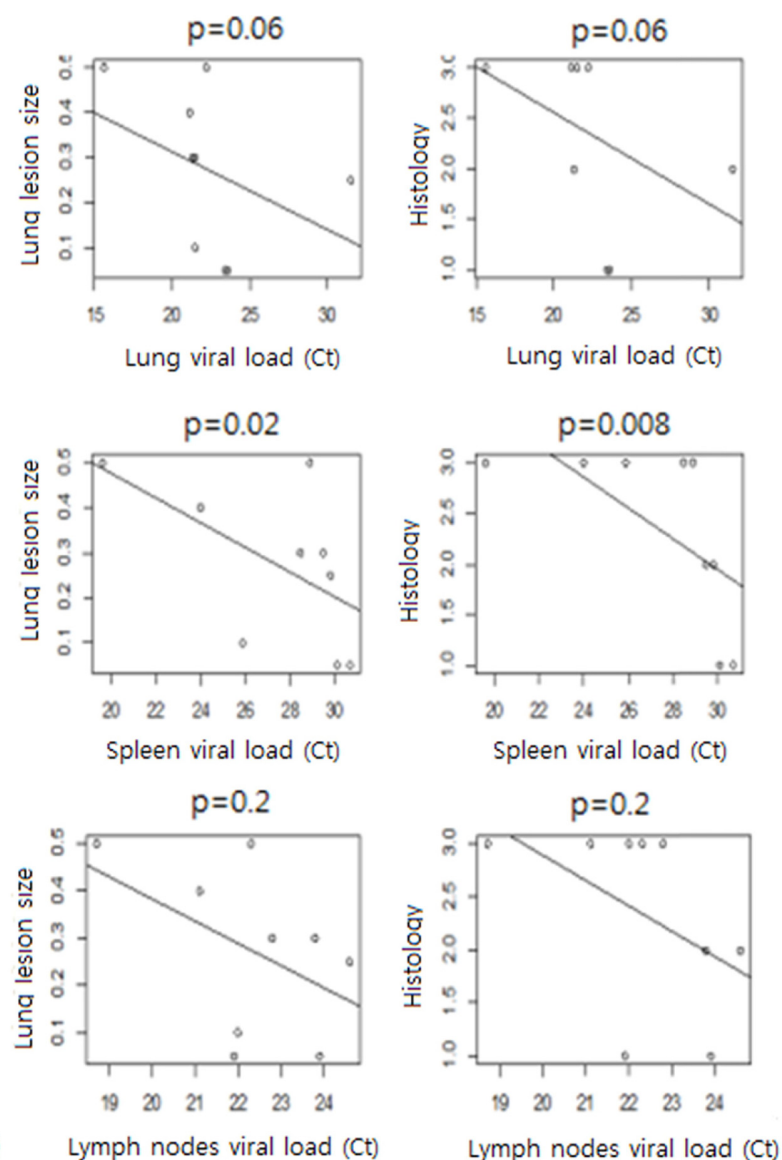

Fig. 2. Statistical correlation analysis between tissue viral loads (A, lung; B, spleen; and C, lymph nodes), PRRSV-infected PAM frequency, macroscopic and microscopic lung lesions. Statistical analysis was performed with data in Table 1.

notypes of T-lymphocyte varied among the piglets (Table 2). Neutralizing antibody titer was $1: 2$ to $1: 16$ at 0 -dpb before colostrum consumption, and was $1: 2$ to $1: 16$ and $1: 8$ to $1: 32$ at 7- and 14-dpb, respectively.

\section{Correlation between different infection parameters}

Correlation between different infection parameters was analyzed in Figure 2 and summarized in Table 3. The viral load in lung tissue had a significantly high positive correla- 
Table 3. Summary on statistical correlation analysis ( $p$ value) between immune parameters and infection parameters in piglets born after in utero infection

\begin{tabular}{|c|c|c|c|c|c|c|c|c|c|c|}
\hline & \multirow[b]{2}{*}{ Piglet ID } & \multirow{2}{*}{$\begin{array}{l}\text { CD172 } \alpha^{+} \\
\text {PRRSV-N }^{+} \\
\text {PAM }\end{array}$} & \multirow{2}{*}{$\begin{array}{c}\text { Gross lung } \\
\text { lesion size } \\
(\%)\end{array}$} & \multirow[b]{2}{*}{$\begin{array}{l}\text { Lung his- } \\
\text { tology }\end{array}$} & \multicolumn{3}{|c|}{ Viral load $(\mathrm{Ct})$ in plasma } & \multicolumn{3}{|c|}{ Viral load $(\mathrm{Ct})$ in tissue } \\
\hline & & & & & $0-\mathrm{dpb}$ & 7-dpb & 14-dpb & Lung & Spleen & $\begin{array}{c}\text { Lymph } \\
\text { node }\end{array}$ \\
\hline \multirow{3}{*}{$\mathrm{T}$ cell } & $\mathrm{CD}^{+} \mathrm{CD}^{+}$ & $0.017 *$ & 0.01 & 0.3 & 0.09 & 0.41 & 0.14 & 0.002 & 0.07 & 0.47 \\
\hline & $\mathrm{CD}^{+} \mathrm{CD}^{+}$ & 0.024 & 0.01 & 0.3 & 0.21 & 0.45 & 0.27 & 0.11 & 0.1 & 0.04 \\
\hline & $\mathrm{CD} 3^{+} \mathrm{CD} 4^{+} \mathrm{CD} 8^{+}$ & 0.003 & 0.07 & 0.06 & 0.05 & 0.03 & 0.02 & 0.000006 & 0.006 & 0.03 \\
\hline \multicolumn{2}{|c|}{ IFN- $\gamma^{2} \mathrm{~T}$ cell SFU } & 0.13 & 0.002 & 0.09 & 0.01 & 0.39 & 0.46 & 0.25 & 0.11 & 0.35 \\
\hline \multicolumn{2}{|c|}{ VN titer } & 0.78 & 0.65 & 0.79 & 0.43 & 0.26 & 0.89 & 0.37 & 0.8 & 0.61 \\
\hline
\end{tabular}

*Statistical analysis was performed with data of Tables 1 and 2. VN, virus neutralizing.

tion with PRRSV-infected PAM frequency $(p=0.01)$, and low positive correlations with gross lung lesion score $(p=$ $0.06)$ and severity of microscopic lesion in lung ( $p=0.06)$. The viral load in spleen tissue was also significantly highly correlated with PRRSV-infected PAM frequency $(p=0.006)$, gross lung lesion score $(p=0.02)$ and severity of microscopic lesion in lung $(p=0.0008)$. The viral load in lymph node had a significantly high positive correlation $(p=0.03)$ with PRRSV-infected PAM frequency, but not with gross lesion score $(p=0.2)$ and histological severity in lung tissue $(p=0.2)$.

\section{Relationship between infection parameters and immune} parameters

Frequencies of T-lymphocyte subpopulations including $\mathrm{CD}^{+} \mathrm{CD}^{+}, \mathrm{CD}^{+} \mathrm{CD}^{+}$and $\mathrm{CD}^{+} \mathrm{CD}^{+} \mathrm{CD}^{+}$in total $\mathrm{PBMC}$ were analyzed for correlation with infection parameters including PRRSV-infected PAM frequency, macroscopic lung lesion score, severity of microscopic lesion in lung, and viral loads in plasma and tissues (Table 3 ). $\mathrm{CD}^{+} \mathrm{CD} 4^{+} \mathrm{CD} 8^{+}$ T-lymphocytes had significantly high inverse correlations with CD172 $\alpha^{+}$PRRSV-N ${ }^{+}$PAM $(p=0.003)$, and viral load in all tissues $(p<0.03)$, but low inverse correlations with macroscopic $(p=0.07)$ and microscopic $(p=0.06)$ lung lesions. $\mathrm{CD}^{+} \mathrm{CD}^{+}$T-lymphocytes had significantly high inverse correlations with various infection parameters including CD172 $\alpha^{+}$PRRSV-N ${ }^{+}$PAM ( $\left.p=0.017\right)$, macroscopic lung lesion score $(p=0.01)$, and viral loads of lung $(p=0.002)$. $\mathrm{CD}^{+} \mathrm{CD}^{+}$ T-lymphocytes had significant inverse correlations with CD172 $\alpha^{+}$PRRSV-N ${ }^{+}$PAM frequency $(p=0.024)$, macroscopic lung lesion score $(p=0.01)$, and viral load in lymph nodes $(p=0.04)$. The frequency of PRRSV-specific IFN- $\gamma$ secreting T-lymphocytes had a significant inverse correlation with macroscopic lung lesion score $(p=0.002)$ and a significant $(p=0.05)$ positive correlation with $\mathrm{CD}^{+} \mathrm{CD}^{+} \mathrm{T}$-lymphocytes (Table 2).

Interestingly, the titer of virus neutralizing (VN) antibodies had no significant inverse correlations with viral loads in plasma $(p=0.89)$, lung $(p=0.37)$, spleen $(p=0.80)$ and lymph nodes $(p=0.61)$ at $14-\mathrm{dpb}$, and other infection parameters including CD172 $\alpha^{+}$PRRSV-N ${ }^{+}$PAM frequency $(p=0.78)$, macroscopic lung lesion score $(p=0.65)$ and severity of microscopic lesion in lung $(p=0.79)$ at $14-\mathrm{dpb}$.

\section{Discussion}

Defining immune protective mechanisms in PRRSV-infected pigs have been focused on neutralizing antibody responses. It has been reported that neutralizing antibodies play a role in protecting pigs from PRRS to a certain extent [25, 34]. Therefore, neutralizing antibody titer has been used in most studies as a criterion to evaluate protective immunity in vaccinated or naturally infected pigs. However, PRRSV-specific neutralizing antibodies were slowly induced, strain-specific and, therefore, not efficacious for controlling antigenically diverse PRRSV isolates including heterogeneous viruses of the same genotype or viruses of different genotypes [4, 23]. Up to date, neutralizing antibody-based evaluation of PRRS vaccines have not resulted in a commercial vaccine efficacious against diverse virus isolates yet. Despite unsuccessful development of efficacious vaccines inducing protective neutralizing antibody responses against heterologous isolates in pigs, systematic approaches to define other protective mechanisms including innate immunity and CMI have been lacking. Therefore, this study was conducted to define immune parameters associated with disease protection in piglets born to a gilt infected with a pathogenic type-2 PRRSV, SD23983 isolate.

Fetal pathogenicity of PRRSV $\mathrm{SD} 23983_{3}$ after in-utero infection varied in different studies. In this study, the gilt infected with PRRSV $\mathrm{SD}_{\mathrm{S} 3983}$ had two still-births (18.2\% of piglets) and 9 live PRRSV-infected births. A previous study using the identical strain reported that $43-58 \%$ of piglets were born live, $24-43 \%$ stillborn and $6-18 \%$ mummified when sows were infected at 98 days of gestation [11]. In contrast, another study reported that the PRRSV infection of sows at 90 days of gestation resulted in $4.5 \%$ of dead piglets [28]. A possible explanation for higher fetal pathogenicity in two of three studies may be related to infection timing in gestation period. Eight-day delayed infection in gestation period may be related to higher rates of reproductive failure $[10,14,16]$. Another possible explanation is that different passage history of PRRSV stocks in green monkey cell line (Marc 145) may 
cause varying virulence [9]. Despite severe pathogenicity of PRRSV $_{\mathrm{SD} 23983}$ in in-utero infected piglets in this study and other previous studies [11, 28], manifestation in the gilt after intranasal infection of PRRSV $\mathrm{SD} 23983_{\text {was }}$ limited to short period of viremia without clinical symptom such as lung lesion and nasal discharge.

All of piglets born to the gilt infected with PRRSV $\mathrm{SD} 23983_{3}$ by intranasal route developed PRRS-specific diseases including clinical symptoms (anorexia, depression, and respiratory syndrome), viremia, viral loads in various lymph nodes, and macroscopical and microscopical lung lesions. PRRSV-specific neutralizing antibody measured by $\mathrm{VN}$ titer and PRRSV-specific T-lymphocytes measured by IFN- $\gamma$ T-cell SFU were detectable at varying levels. VN titers in infected live birth piglets were ranging from $1: 2$ to $1: 16\left(1-4 \log _{2}\right)$ at 0 -dpb before colostrum consumption, and reached to 3-5 $\log _{2}$ at 14-dpb. Despite weak VN titers of in-utero infected piglets, higher VN positive rate $(100 \%)$ at birth was noticeable than a previous report [28] with positive VN titers in only $22 \%$ of piglets in-utero infected at 90 days of gestation. Increasing VN titers in 9 piglets at later dpbs suggest that neutralizing antibody responses in the infected piglets are not solely due to passive transfer through colostrum of the gilt. No significant difference in VN titer among piglets with various levels in disease parameters may support that neutralizing antibodies may not be a protection correlate in in-utero PRRSV-infected piglets.

Significantly high positive correlations between various PRRSV infection parameters in piglets born after in-utero infection were demonstrated in this study. The viral loads in lung, spleen and lymph nodes had significant positive correlations with PRRSV-infected PAM frequency. Viral loads in lung were also significantly correlated with macroscopic lung lesion score of PRRS-infected piglets. Since PAM in PRRSVinfected pigs is the main target cell in which virulent PRRSVs actively replicate [9, 35], significant correlation between PRRSV-infected PAM frequency and viral loads in lymph nodes in in-utero infected piglets demonstrates that PAM infectivity is a good indicator for respiratory virulence of PRRSV SD23983 strain than microscopic lesion using focal tissue samples in PRRS affected lung.

Significantly high inverse correlations between PRRS disease parameters and protective CMI parameters induced in piglets born after in-utero infection were demonstrated as a major finding in this study. Percentages of three T-lymphocyte subpopulations in the in-utero infected piglets had a significant inverse correlation with macroscopic lung lesion score. Particularly, $\mathrm{CD}^{+} \mathrm{CD} 4^{+} \mathrm{CD} 8^{+} \mathrm{T}$-lymphocytes were significantly associated with lower viral load in plasma and tissues. Previous reports on IFN- $\gamma$ secreting cells in lung of PRRSV-infected pigs [29, 30], and the protective correlation between IFN- $\gamma$ secreting cells in PBMC and control of pseudorabies [36] led to expectation on contribution of CMI in the control of PRRSV in infected pigs. PRRSV-specific Tlymphocyte response determined by IFN- $\gamma$ ELISPOT assay was significantly associated with reduction of reproductive failures in swine farms [20]. IFN- $\gamma$ response was first reported in PRRSV-infected fetuses, suggesting the capability of fetuses to develop virus-specific T-lymphocyte responses [28]. However, the protective role of the IFN- $\gamma$ secreting cells has not been systematically studied yet. In this study, the number of IFN- $\gamma$ secreting T-lymphocytes in PBMC of the piglets in-utero infected with type- 2 PRRSV $_{\mathrm{SD}_{23983}}$ had a highly significant $(p=0.002)$ inverse correlation with macroscopic lung lesion of those infected piglets, suggesting that IFN- $\gamma$ secreting cells developed in the in-utero PRRSVinfected fetuses may be associated with protection against neonatal PRRS development after birth. In addition, number of IFN- $\gamma$ secreting cells had a significant $(p=0.05)$ positive correlation with percentage of $\mathrm{CD}^{+} \mathrm{CD}^{+} \mathrm{T}$ lymphocytes in PBMC, indicating that IFN- $\gamma$ secreting cells may be mainly composed of $\mathrm{CD}^{+} \mathrm{CD}^{+} \mathrm{T}$ lymphocytes. Therefore, even though previous reports $[8,18]$ could not define the clear functional roles of T-lymphocytes in controlling PRRS and PRRSV replication in tissues, the positive correlation between $\mathrm{CD}^{+} \mathrm{CD}^{+} \mathrm{T}$-lymphocytes and PRRSV-specific IFN- $\gamma$ secretion in in-utero infected piglets in this study suggests the potential protective role of the T-lymphocyte subpopulations. Simple correlation results based on frequencies of Tlymphocyte subpopulations and PRRSV-specific total T-lymphocytes induced in piglets after intra-uterine infection of PRRSV in this study need to be further characterized using other functional T-lymphocyte assays directly related to elimination of RRSV-infected target cells in infected pigs as reported in lentivirus infection [6]. One of our ongoing studies to further characterize protective T-lymphocyte responses demonstrated cytotoxic responses by both $\mathrm{CD} 8^{+}$and $\mathrm{CD} 4^{+} \mathrm{T}-$ lymphocytes in three $\mathrm{PRRSV}_{\mathrm{SD} 23983}$-infected gilts (data not shown).

This study reports that the disease severity of in-utero PRRSV $_{\mathrm{SD} 23983}$-infected piglets is inversely associated with the numbers of major T-lymphocyte subpopulations and PRRSVspecific IFN- $\gamma$ secreting T-cells, but not with the level of PRRSV-specific neutralizing antibodies. Further study will be needed to define protective mechanisms of PRRSV-specific T-lymphocyte responses and their efficacies in various age groups of pig.

\section{Acknowledgments}

The authors are grateful to Ms. Grace Chung for critical review of manuscript. This study was funded by Animal and Plant Quarantine Agency, Republic of Korea (QIA I1543083-2015-16-01).

\section{References}

1. Bøtner A, Strandbygaard B, Sørensen KJ, Have P, Madsen KG, Madsen ES, Alexandersen S. Appearance of acute PRRS-like symptoms in sow herds after vaccination with a modified live PRRS vaccine. Vet Rec 1997, 141, 497499. 
2. Cano JP, Dee SA, Murtaugh MP, Trincado CA, Pijoan C. Effect of vaccination with a modified-live porcine reproductive and respiratory syndrome virus vaccine on dynamics of homologous viral infection in pigs. Am J Vet Res 2007, 68, 565-571.

3. Choi K, Lee J, Park C, Jeong J, Chae C. Comparison of the pathogenesis of single or dual infections with type 1 and type 2 porcine reproductive and respiratory syndrome virus. $\mathrm{J}$ Comp Pathol 2015, 152, 317-324.

4. Choi K, Park C, Jeong J, Chae C. Comparison of protection provided by type 1 and type 2 porcine reproductive and respiratory syndrome field viruses against homologous and heterologous challenge. Vet Microbiol 2016, 191, 72-81.

5. Chung CJ, Cha SH, Grimm AL, Chung G, Gibson KA, Yoon KJ, Parish SM, Ho CS, Lee SS. Recognition of highly diverse type-1 and -2 porcine reproductive and respiratory syndrome viruses (PRRSVs) by T-lymphocytes induced in pigs after experimental infection with a type-2 PRRSV strain. PLoS One 2016, 11, e0165450.

6. Chung C, Lee W, Loffredo, JT, Burwitz B, Friedrich TC, Giraldo Vela JP, Napoe G, Rakasz EG, Wilson NA, Allison DB, Watkins DI. Not all cytokine-producing $\mathrm{CD}^{+}$ $\mathrm{T}$ cells suppress simian immunodeficiency virus replication. $\mathrm{J}$ Virol 2007, 81, 1517-1523.

7. Collins JE, Benfield DA, Christianson WT, Harris L, Hennings JC, Shaw DP, Goyal SM, McCullough S, Morrison RB, Joo HS, Gorcyca D, Chladek D. Isolation of swine infertility and respiraoty syndrome virus (isolate ATCC VR-2332) in North America and experimental reproduction of the disease in gnotobiotic pigs. J Vet Diagn Invest 1992, 4, 117-126.

8. Costers S, Lefebvre DJ, Goddeeris B, Delputte PL, Nauwynck HJ. Functional impairment of PRRSV-specific peripheral $\mathrm{CD}^{+} \mathrm{CD}^{\text {shigh }}$ cells. Vet Res 2009, 40, 46.

9. Delputte PL, Nauwynck HJ. Porcine arterivirus infection of alveolar macrophages is mediated by sialic acid on the virus. J Virol 2004, 78, 8094-8101.

10. Done SH, Paton DJ. Porcine reproductive and respiratory syndrome: clinical disease, pathology and immunosuppression. Vet Rec 1995, 136, 32-35

11. Feng W, Laster SM, Tompkins M, Brown T, Xu JS, Altier C, Gomez W, Benfield D, McCaw MB. In utero infection by porcine reproductive and respiratory syndrome virus is sufficient to increase susceptibility of piglets to challenge by Streptococcus suis type II. J Virol 2001, 75, 4889-4895.

12. Halbur PG, Paul PS, Frey ML, Landgraf J, Eernisse K, Meng XJ, Lum MA, Andrews JJ, Rathje JA. Comparison of the pathogenicity of two US porcine reproductive and respiratory syndrome virus isolates with that of the Lelystad virus. Vet Pathol 1995, 32, 648-660.

13. Han K, Seo HW, Shin JH, Oh Y, Kang I, Park C, Chae C. Effect of the modified live porcine reproductive and respiratory syndrome virus (PRRSV) vaccine on European and North American PRRSV shedding in semen from infected boars. Clin Vaccine Immunol 2011, 18, 1600-1607.

14. Karniychuk UU, De Spiegelaere W, Nauwynck HJ. Porcine reproductive and respiratory syndrome virus infection is associated with an increased number of Sn-positive and CD8-positive cells in the maternal-fetal interface. Virus Res
2013, 176, 285-291.

15. Kim HS, Kwang J, Yoon IJ, Joo HS, Frey ML. Enhanced replication of porcine reproductive and respiratory syndrome (PRRS) virus in a homogeneous subpopulation of MA-104 cell line. Arch Virol 1993, 133, 477-483.

16. Kranker S, Nielsen J, Bille-Hansen V, Bøtner A. Experimental inoculation of swine at various stages of gestation with a Danish isolate of porcine reproductive and respiratory syndrome virus (PRRSV). Vet Microbiol 1998, 61, 21-31.

17. Li X, Galliher-Beckley A, Pappan L, Trible B, Kerrigan M, Beck A, Hesse R, Blecha F, Nietfeld JC, Rowland RR, Shi J. Comparison of host immune responses to homologous and heterologous type II porcine reproductive and respiratory syndrome virus (PRRSV) challenge in vaccinated and unvaccinated pigs. Biomed Res Int 2014, 2014, 416727.

18. Lohse L, Nielsen J, Eriksen L. Temporary $\mathrm{CD}^{+}$T-cell depletion in pigs does not exacerbate infection with porcine reproductive and respiratory syndrome virus (PRRSV). Viral Immunol 2004, 17, 594-603.

19. López Fuertes L, Doménech N, Alvarez B, Ezquerra A, Domínguez J, Castro JM, Alonso F. Analysis of cellular immune response in pigs recovered from porcine respiratory and reproductive syndrome infection. Virus Res 1999, 64, $33-42$.

20. Lowe JE, Husmann R, Firkins LD, Zuckermann FA, Goldberg TL. Correlation of cell-mediated immunity against porcine reproductive and respiratory syndrome virus with protection against reproductive failure in sows during outbreaks of porcine reproductive and respiratory syndrome in commercial herds. J Am Vet Med Assoc 2005, 226, 17071711.

21. Meier WA, Husmann RJ, Schnitzlein WM, Osorio FA, Lunney JK, Zukermann FA. Cytokines and synthetic double-stranded RNA augment the $\mathrm{T}$ helper 1 immune response of swine to porcine reproductive and respiratory syndrome virus. Vet Immunol Immunopathol 2004, 102, 299314.

22. Molina RM, Cha SH, Chittick W, Lawson S, Murtaugh MP, Nelson EA, Christopher-Hennings J, Yoon KJ, Evans R, Rowland RRR, Zimmerman JJ. Immune response against porcine reproductive and respiratory syndrome virus during acute and chronic infection. Vet Immunol Immunopathol 2008, 126, 283-292.

23. Murtaugh MP, Xiao Z, Zuckermann F. Immunological responses of swine to porcine reproductive and respiratory syndrome virus infection. Viral Immunol 2002, 15, 533-547.

24. Nielsen HS, Oleksiewicz MB, Forsberg R, Stadejek T, Botner A, Storgaard T. Reversion of a live porcine reproductive and respiratory syndrome virus vaccine investigated by parallel mutations. J Gen Virol 2001, 82, 1263-1272.

25. Osorio FA, Galeota JA, Nelson E, Brodersen B, Doster A, Wills R, Zuckermann F, Laegreid WW. Passive transfer of virus-specific antibodies confers protection against reproductive failure induced by a virulent strain of porcine reproductive and respiratory syndrome virus and establishes sterilizing immunity. Virology 2002, 302, 9-20.

26. Park C, Seo HW, Kang I, Jeong J, Choi K, Chae C. A new modified live porcine reproductive and respiratory syndrome vaccine improves growth performance in pigs 
under field conditions. Clin. Vaccine Immunol 2014, 21, 1350-1356.

27. Reed LJ, Muench H. A simple method of estimating fifty percent endpoints. Am J Hygiene 1938, 27, 493-497.

28. Rowland RRR. The interaction between PRRSV and the late gestation pig fetus. Virus Res 2010, 154, 114-122.

29. Thanawongnuwech R, Rungsipipat A, Disatian S, Saiyasombat R, Napakanaporn S, Halbur PG. Immunohistochemical staining of IFN- $\gamma$ positive cells in porcine reproductive and respiratory syndrome virus-infected lungs. Vet Immunol Immunopathol 2003, 91, 73-77.

30. Thanawongnuwech R, Thacker EL. Interleukin-10, interleukin-12, and interferon- $\gamma$ levels in the respiratory tract following Mycoplasma hyopneumoniae and PRRSV infection in pigs. Viral Immunol 2003, 16, 357-367.

31. Wensvoort G, Terpstra C, Pol JMA, ter Laak EA, Bloemraad M, de Kluyver EP, Kragten C, van Buiten L, den Besten A, Wagenaar F, Broekhuijsen JM, Moonen PLJM, Zetstra T, de Boer EA, Tibben HJ, de Jong MF, van 't Veld P, Greenland GJR, van Gennep JA, Voets MTh, Verheijden JHM, Braamskamp J. Mystery swine disease in The Netherlands: the isolation of Lelystad virus.
Vet Q 1991, 13, 121-130.

32. Wu WH, Fang Y, Farwell R, Steffen-Bien M, Rowland RRR, Christopher-Hennings J, Nelson, EA. A 10-kDa structural protein of porcine reproductive and respiratory syndrome virus encoded by ORF2b. Virology 2001, 287, 183-191.

33. Xiao Z, Batista L, Dee S, Halbur P, Murtaugh MP. The level of virus-specific T-cell and macrophage recruitment in porcine reproductive and respiratory syndrome virus infection in pigs is independent of virus load. J Virol 2004, 78, 59235933.

34. Yoon IJ, Joo HS, Goyal SM, Molitor TW. A modified serum neutralization test for the detection of antibody to porcine reproductive and respiratory syndrome virus in swine sera. J Vet Diagn Invest 1994, 6, 289-292.

35. Zhang Q, Yoo D. PRRS virus receptors and their role for pathogenesis. Vet Microbiol 2015, 177, 229-241.

36. Zuckermann FA, Martin S, Husmann RJ, Brandt J. Use of interleukin 12 to enhance the cellular immune response of swine to an inactivated herpesvirus vaccine. Adv Vet Med 1999, 41, 447-461. 